\title{
СОЦИАЛЬНО-КРИМИНОЛОГИЧЕСКИЙ ПОРТРЕТ СОВРЕМЕННОГО КОРРУПЦИОНЕРА
}

\section{SOCIO-CRIMINOLOGICAL PORTRAIT OF A MODERN CORRUPTIONER}

\section{Yavorsky \\ M. Stepanov}

Summary: The article attempts a comprehensive analysis of the most significant socio-criminological aspects of corruption crime, with an emphasis on the study of individual dominants of individuals who are potentially focused on such deviant behavior. The presented research focuses on the analysis of the personality features of a modern corrupt official, with the identification of its negative attitudes, individual dominants, which are the results of psychological deformation; The author's socio-criminological portrait describing the type of the generalized subject of corruption-related crimes is proposed.

Keywords: corruption, individual characteristics, criminological portrait, modern corrupt official.

\author{
Яворский Максим Александрович \\ К.ю.н., дочент, Самарский государственный \\ экономический университет \\ yavorm@mail.ru \\ Степанов Михаил Евгеньевич \\ Самарский государственный экономический \\ университет \\ step060696@mail.ru
}

Аннотация: B статье предпринята попытка комплексного анализа наиболее значимых социально-криминологических аспектов коррупционной преступности, с акцентом на изучение индивидуальных доминант лиц, потенциально ориентированных на подобное девиантное поведение. Представленное исследование сосредоточено на анализе особенностей личности современного коррупционера, с выявлением ее негативных установок, индивидуальных доминант, являющихся результатов психологической деформации; предложен авторский социально-криминологический портрет, описывающий типаж обобщенного субъекта преступлений коррупционной направленности.

Ключевые слова: коррупция, индивидуальные характеристики, криминологический портрет, современный коррупционер.

ные законом. Законопослушного гражданина отличает адекватная самооценка, он ставит перед собой общественно полезные цели и стремится при их достижении занять достойное место в социуме [1, с. 41].

Кардинально другое мировосприятие присуще коррупционеру. На первое место у него выходят негативные установки, через призму которых он оценивает все, что происходит с ним и вокруг него. Система ценностей у рассматриваемой категории лиц искажена [2]. Критика собственного поведения и значимых действий у них зачастую полностью отсутствует или снижена. Подобные субъекты безразлично относятся к общественному мнению, равнодушно воспринимая внешние «месседжи». Иногда имеет место западение самооценки, что связано с ситуацией, когда по каким-то причинам человек не нашел себя в социуме или считает себя недооцененным окружающими.

Не вызывает сомнений, что фундаментальные морально-нравственные принципы, являются результатом конкретных социальных процессов. Между этими звеньями существует прямая зависимость. Насколько этические установки, воспринимаются конкретным лицом, способен ли он к их правильному применению в складывающихся обстоятельствах, определяет его дальнейшие поступки. В итоге нередко формируется тип личности с четкой криминальной установкой, ориентированный на совершение коррупционных преступлений. 
С одной стороны, коррупционер - это умышленный преступник, с устойчивой криминальной направленностью личности. Поэтому у него выделяются общие черты, свойственные всем представителям криминального сообщества. С другой стороны, данная преступная группа настолько специфична, что для нее характерен целый ряд индивидуальных отличий [3], которые мы попытаемся обозначить. В то же время внешне эти лица выглядят, как законопослушные граждане.

Методом случайной выборки нами были изучены по специальной программе пятьдесят уголовных дел по коррупционным составам, что позволило получить результаты, отличающиеся репрезентативностью. В частности, обобщение материалов показало, что лица, привлекаемые к ответственности, за взяточничество, как правило, имеют семью (93\%). Они состоят в браке, воспитывают несовершеннолетних детей, в среднем не меньше двух (61\%). В бытовых характеристиках содержатся сведения о них, как заботливых супругах и родителях. Более того, получение незаконного вознаграждения они нередко пытаются объяснить сложностями материального положения своей семьи, желанием помочь кому-то из близких решить возникшие проблемы (по 97\% дел).

С позиций отношения к служебным обязанностям изучаемые субъекты проявляют себя, как добросовестные работники. Они демонстрируют высокий уровень профессиональной компетентности, что позволяет им добиваться карьерного роста, причем достаточно быстрого. До момента возбуждения уголовного дела данные лица показывают себя исключительно с положительной стороны, отличаясь служебным рвением, корпоративной преданностью, умением строить отношения с руководством и в коллективе. Все перечисленные факторы отражаются в их служебных характеристиках, представляемых работодателями в ходе расследования преступлений (98\%).

По изученным уголовным делам установлено, что подавляющее большинство фигурантов имеют высшее образование (89\%), в ряде случае не одно (15\%). Обращает на себя внимание следующий фактор: по 54\% дел у обвиняемых было экономическое или юридическое образование, у остальных техническое (35\%), в том числе, в сфере программирования (18\%). По конкретным уголовным делам никто из обвиняемых не имел каких-либо психических отклонений, не состоял на учете у психиатра (100\%).

В целом мировоззрение указанных субъектов на момент совершения противоправных действий коррупционного характера оценивается, как полностью сформировавшееся. При этом они отличались работоспособностью, исполнительской дисциплиной, креативностью мышления. Таким образом, их деловые качества по общепринятой оценочной шкале можно обозначить как высокие, личностные характеристики соответствуют среднестатистическому уровню.

В криминологической литературе длительное время отстаивался тезис, что к совершению актов коррупции фигурантов подталкивают финансовые проблемы. Между тем современные исследования опровергают подобное понимание. Они подкреплены статистическими выкладками, согласно которым подавляющее большинство коррупционеров относятся к категории лиц с высоким (или выше среднего) материальным уровнем. По изученным делам усматривалось, что у $66 \%$ обвиняемых доход был выше среднего. Данный фактор имеет объективную составляющую, поскольку приметой последнего времени стало привлечение к уголовной ответственности лиц, имеющих отношение к высшим эшелонам власти. Последние в ряде случае занимали посты государственной и муниципальной службы (11\%), работали в правоохранительных органах (7\%).

Субъекты коррупционной деятельности по наличию публичного статуса условно делятся на два типа:

1. представители высшего эшелона власти, обладающие широким объемом полномочий, необходимых для осуществления определенной государственной функции (этому сегменту свойственно взяточничество в виде получения незаконного вознаграждения за действия, входящие в круг их служебных обязанностей, но в данном случае они используют эти полномочия в корыстных целях);

2. лица, которые выступают, как взяткодатели, и стремятся таким образом получить лично для себя некие незаконные преимущества.

Нами предпринята попытка обозначить структуру субъектов преступлений данной группы по степени их подверженности коррупции. По этому критерию выделяется пласт чиновников. Как правило, это представители исполнительной власти, обладающие организационно-распорядительными функциями, имеющие доступ к бюджетным средствам и значительный объем компетенции. В их числе, руководители министерств и ведомств, их заместители; главы регионов, городов и других населенных пунктов; сотрудники правоохранительных органов; судьи; должностные лица органов, осуществляющих разные виды контроля; работники служб - судебных приставов-исполнителей, налоговой, таможенной, миграционной. В другой ветви власти - законодательной случаи коррупции также имеют место быть, но выявляются они, имея в качестве продолжения возбуждение дела с полноценным расследованием и постановлением обвинительного приговора намного реже. Объективно это имеет свои причины, прежде всего, в виде индульгенции от привлечения представителей депутатского корпуса к уголовной ответственности, в связи с нали- 
чием у них статуса неприкосновенности (депутатский иммунитет). Ученые и представители общественных организаций неоднократно указывают на необходимость отмены упомянутой привилегии, что, безусловно, будет иметь положительный эффект и снимет двойные стандарты в этом кластере.

Как показало изучение уголовных дел по коррупционным составам, рецидив в рассматриваемом сегменте преступлений незначителен, порядка 4\%, причем в 96\% случаев это лица, которые являлись посредниками в передаче незаконного вознаграждения. От общего количества всех осужденных за коррупционные действия, больше половины получили взятку при отягчающих обстоятельствах; значительная часть - это субъекты, оказывающие посредничество в передаче незаконного вознаграждения.

Специальный рецидив дает только мнимое посредничество, под которым понимают ситуацию, когда некое лицо предлагает посреднические услуги взяткодателю. В этом случае оно берет от него денежные средства или ценности, убеждая его в том, что они будут переданы конкретному должностному лицу в качестве взятки за определенные действия в интересах дающего. Однако по факту незаконное вознаграждение никому не передается, а предмет взятки просто присваивается.

Здесь возможны криминальные вариации. В первом случае до самого момента завладения деньгами, мошенник уверяет потенциального взяткодателя в том, что у него близкие отношения с чиновником и это позволит ему решить тот вопрос, который интересует дающего. Во втором случае, взяткодателю намеренно передается несоответствующая действительности информация о возможностях посредника, якобы контактирующего с должностным лицом. Исходя из этого ложного посыла, взяткодатель сам пытается уговорить предполагаемого посредника передать незаконное вознаграждение. Причем последний, соглашается на это только после длительных уговоров, явно демонстрируя отсутствие личной заинтересованности в такой передаче.

Ряд исследователей провели анкетирование среди лиц, ранее осужденных за подобные преступления. Более 70\% из них заявили, что им было известно о незаконности совершаемых действий. При этом $96 \%$ респондентов рассчитывали на свою безнаказанность и были убеждены в том, что смогут избежать наказания. Подавляющее большинство опрошенных считали, что суд определил им чрезмерно суровое наказание, оценивали его, как несправедливое [4, с. 203].

Изучение личности коррупционеров по конкретным уголовным делам региональной судебной практики в сопоставлении их со статистическими данными выяви- ло, что возрастные показатели лиц, совершающих такого рода преступления, имеют тенденцию к снижению. Буквально 10-15 лет тому назад взяточничество в форме получения незаконного вознаграждения было характерно для лиц, в сегменте 37 - 38 лет. В настоящее время это более молодая возрастная группа, около 32 - 33 лет (87\%). Объективно подобное омоложение связано с тем, что молодежь сразу после получения образования начинает активно заниматься построением карьеры, добиваясь определенного служебного роста именно в этих возрастных границах.

Возраст взяткодателей несколько выше, в сегменте 35 - 50 лет, то есть охватывает практически весь период активной трудовой деятельности. В случае группового взяточничества, основной фигурант, чаще всего, старше по возрасту, соучастники моложе. Организатор коррупционного преступления, вовлекая их в криминальную схему, нередко пользуется своим личным авторитетом и служебным положением. Фактически в числе его подельников оказываются подчиненные. Однако их противоправная деятельность никак не является проявлением исполнительской дисциплины, а образует состав коррупционного преступления.

Установленная по результатам исследования возрастная граница и социальный статус субъекта коррупционной деятельности вполне понятны, поскольку речь о возможности принятия решения о совершении заведомо незаконных действий, с использованием свои служебных полномочий. Последние соответствуют статусу руководителя, с широкой областью компетенции и доступом к финансовым потокам и имуществу организации.

Прежде чем получить должность такого высокого уровня, лицо должно получить высшее образование, сделать карьеру, пройдя по ней ряд ступеней, у него имеется определенный трудовой стаж. Такой фигурант обладает личным жизненным опытом, деловыми контактами, нередко по вышестоящей линии, в муниципальных структурах и правоохранительных органах. У него зачастую безупречная репутация и внешне он выглядит респектабельно.

Изучая уголовные дела данной категории, мы обратили внимание на то, что их фигурантами, в основном, были руководители. Вполне объяснимый факт, поскольку именно у этих должностных лиц есть потенциальная возможность заниматься коррупционной деятельностью.

Тенденцией последнего времени стало появление в этом сегменте лиц высшего звена государственной службы. При наличии группы, в качестве соучастников они привлекают сотрудников-подчиненных. Коррупцио- 
неры вообще редко действуют по одному. Им свойственно искать единомышленников и объединяться по принципу криминальных сообществ. Проанализированные уголовные дела показывают, что нередко их фигуранты имели длительные отношения и знали друг друга до начала совместной противоправной деятельности. Например, вместе служили в армии; работали; учились; были родственниками и друзьями. В этой связи мы согласны с мнением ряда авторов, что взяточничество подпитывается протекционизмом, фаворитизмом и непотизмом (от лат. nepos, род. п. nepotis «внук; племянник»).

С точки зрения половой принадлежности, в недавнем прошлом, это были практически на сто процентов мужские преступления. В настоящее время противоправные действия коррупционной направленности совершают и женщины (28\% от общего количества изученных уголовных дел). Причем доля женщин среди данной категории преступников почти в два раза выше, чем доля женщин во всех остальных преступлениях.

В теории пристальное внимание уделено изучению мотивов поведения коррупционера. Ранее считалось, что единственным для этого вида преступлений является корыстный мотив. Однако в настоящее время сложилось иное понимание. Многие авторы полагают, что подобные действия зачастую совершаются по причине жажды власти, из желания быстро и любым способом сделать карьеру. Указанные субъекты стремятся стать заметными, выделиться из общей массы, завоевать авторитет у окружающих. В этой связи корысть, безусловно, у них присутствует, однако она не основной мотив, а субсидиарный.

Субъект, склонный к коррупционным проявлениям, все же ориентирован на получение материальных ценностей, иная составляющая для него менее важна. При возникновении коллизии между общественным и личными интересами, он всегда делает выбор в пользу последних. Большинство фигурантов подобных дел страдают от вещизма, стремясь к бессмысленной роскоши. Показательно в этом смысле уголовное дело в отношении экс-главы Республики Коми Вячеслава Гайзера, в ходе которого был проведен обыск в рабочем кабинете губернатора. При этом были обнаружены денежные средства в весьма значительной сумме, коллекция часов (30 часов различных марок), со стоимостью каждого экземпляра порядка одного миллиона долларов и ручка из чистого золота.

У лиц, совершающих преступления такого рода отсутствует «антикоррупционная устойчивость» [5]. Они не способны сказать твердое «Нет!» предложениям о незаконном вознаграждении. Сложность нравственного выбора, завершающегося принятием решения о допустимости для конкретного субъекта подобных действий, перерастает, как правило, в системное поведение, когда получение взятки становится для таких лиц нормой и обыденностью. Более того, они нередко пытаются подвести под свои противоправные действия определенную идеологию, стараясь оправдать их совершение, например, служебными интересами. По существу человек признает за собой право на стяжательство, после чего нравственная деградация происходит весьма быстро. Одновременно с разрушением социальных установок, обесцениванием того, что прежде было значимо и дорого, у коррупционера формируются свои искаженные представления о допустимом поведении, справедливости.

В теории выделяются некоторые показатели, которые позволяют определить наличие у субъекта предрасположенности к коррупционным проявлениям. В их числе оценка степени удовлетворенности уровнем жизни, полученной профессией, своим личным статусом и самооценкой.

С позиций удовлетворенности уровнем жизни выделяют высокие, средние и низкие значения. Естественно, чем выше уровень удовлетворенности, тем более устойчиво лицо к коррупционно-провоцирующим факторам. Уровень нравственного развития личности, ее правовой культуры напрямую связан со способностью контроля за своим поведением. В этом смысле есть понимание, что надо самому управлять свой жизнью, определяя ее направленность. Однако есть устойчивое мнение, что человека делает его окружение, а все его поступки предопределены.

Исходя из этого, представители психологической науки говорят о так называемых локусах контроля: 1) интернальном; 2) экстернальном.

Представители первого разряда полагают, что за все события, происходящие с ними, они несут личную ответственность, значимые решения ими принимаются самостоятельно. Для коррупционеров такое поведение несвойственно, большинство из них относится к второму локусу контроля, пытаясь переложить ответственность на внешние факторы, им свойственны фаталистические настроения [6, с. 317-319].

С точки зрения поведенческого уровня выделяют несколько типов реагирования: импульсивный и рефлексивный. Первому виду свойственно спонтанное эмоциональное реагирование на внешние раздражители. Второму виду присущ детальный логический анализ происшедшего, с попыткой оценить свои действия в конкретной ситуации, с высоким уровнем критики и возможность сделать выводы из случившегося. Мы присоединяемся к мнению, высказанному рядом авторов, что к коррупционной деятельности, склонны в большинстве 
своем представители импульсивного типа реагирования [7, с. 106].

Проведенное исследование позволило нам сформулировать следующие выводы.

1. В самом общем виде психологический портрет современного коррупционера характеризуется тем, что это полностью сформированная личность, с искаженными нравственными установками. Ей присущ экстернальный локус контроля, импульсивные реакции. Проведенное исследование, обобщение материалов изученных уголовных дело показало, что большинство коррупционных преступлений совершаются мужчинами (72\%). Однако в последнее время отмечается устойчивый рост числа женщин, совершающих подобные противоправные деяния, как правило, они выполняют посреднические функции при передаче незаконного вознаграждения.

2. Подавляющему большинству взяточников свойственна неоправданно завышенная самооценка, сопровождающаяся отсутствием внутреннего контроля за своими поступками. Данные лица отличаются ярко выраженной амбициозностью, в сочетании с убежденностью, что общество их недооценивает.

3. Мотив совершения преступления, у коррупционеров, как правило, корыстный, во главу угла ими ставятся личные интересы, стремление незаконно обогатиться; эти лица достаточно циничны; неуважительно относятся к окружающим, хотя в открытую конфронтацию вступают редко, маскируя свою деятельность под законопослушное поведение. Рецидив для коррупционных преступлений, как правило, не характерен.

4. Социально-криминологический портрет современного коррупционера выглядит следующим образом: это мужчина, в возрасте 35 лет, ранее не судимый, имеющий высшее образование, женатый, воспитывающий малолетних детей, хороший муж, заботливый сын и отец, занимает высокую должность, на службе пользуется авторитетом у вышестоящего руководства и подчиненных, достаточно быстро сделал карьеру, проявил себя, как компетентный специалист, профессионал, с высоким уровнем исполнительской дисциплины и нестандартным мышлением.

5. Среди причин, которые способствуют тому, что обычный гражданин становится коррупционером, следует отметить экономическую нестабильность; снижение рычагов государственного контроля; не последовательность действий в борьбе с взяточничеством; достаточно нейтральное отношение общества к проявлениям коррупции, где подавляющее большинство населения не осуждает подобные акты, воспринимая их, как норму.

6. Подобные преступления имеют потенциальную жертву - это либо тот, у кого вымогают взятку, либо тот, кто пытается ее дать, провоцируя на получение незаконного вознаграждения должностное лицо. Данным лицам коррупционными действиями причиняется материальный ущерб.

7. Профилактическую работу с коррупционными проявлениями, возможно, оптимизировать путем создания банка данных взяточников, причем не только тех, в отношении которых имело место привлечение куголовной ответственности и осуждение, но и тех, по которым имеется оперативная информация о совершении подобных действий или о планировании таковых. Систематизацию данных целесообразно проводить в цифровом формате, что позволит своевременно пополнять банк, внося в него дополнительные сведения и проводя необходимые корректировки.

\section{ЛИТЕРАТУРА}

1. Сердюк Л.В. К вопросу о понятии коррупции и мерах её предупреждения // Российская юстиция. 2011. № 2. С. 41-43.

2. Журавлев А.Л., Юревич А.В. Психологические факторы коррупции // Прикладная юридическая психология. 2012. № 1. URL: https://cyberleninka.ru/ article/n/psihologicheskie-faktory-korruptsii (дата обращения: 06.03.2021).

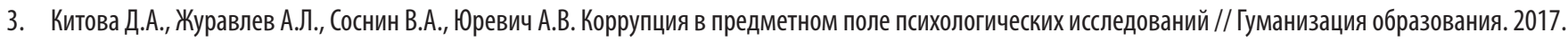
№5. URL: https://cyberleninka.ru/article/n/korruptsiya-v-predmetnom-pole-psihologicheskih-issledovaniy (дата обращения: 06.03.2021).

4. Антонян Ю.М., Эминов В.Е. Личность преступника. Криминолого-психологическое исследование: монография. М.: Норма, Инфра-М, 2015. 368 с.

5. Пастушеня А.Н. Антикоррупционная устойчивость личности: психологическая характеристика // Вестник MГУKИ. 2013. №6 (56). URL: https://cyberleninka. ru/article/n/antikorruptsionnaya-ustoychivost-lichnosti-psihologicheskaya-harakteristika (дата обращения: 06.03.2021).

6. Абдуразаков М.В. Основные направления осуществления антикоррупционной политики в России // Молодой ученый. 2018. № 21. С. 317-319.

7. Степаненко Ю.С., Степаненко Д.Ю. Проблемы борьбы с коррупцией на современном этапе // Закон и право. 2018. № 7. С. $104-106$.

(с) Яворский Максим Александрович (yavorm@mail.ru), Степанов Михаил Евгеньевич (step060696@mail.ru). 